\section{Commentary: Knowing when to accept and when to change: $30-$ day mortality is good enough}

\section{Brian Mitzman, MD}

For several decades, New York State (NYS) has taken a leadership role in evaluating and publicly reporting quality metrics for cardiac surgery. Through rigorous analysis, adjusted mortality rates, readmission rates, and volume are all evaluated by the NYS Department of Health and then reported to the public not only by hospital, but by surgeon. ${ }^{1}$ Thirty days has typically been the postoperative threshold for analysis of mortality, but does is it truly a long enough time frame to capture all negative perioperative outcomes after coronary artery bypass grafting? Mittel and colleagues ${ }^{2}$ explore the appropriateness of a 30-day threshold by comparing it with 90-day mortality and how this change affects institutional benchmark rankings.

The authors linked 3 separate databases to perform this statewide analysis. Discharge data came from the NY Statewide Planning and Research Cooperative System. Mortality was then pulled from the NYS and New York City Vital Records, and hospital level variables were gathered from the American Hospital Association Database. This allowed for enough granularity to evaluate more than 72,000 patients from 42 hospitals. Mittel and colleague's main outcome was to assess whether hospital performance and benchmark status changed with the extended mortality time frame. In short-it did not. Although mortality increased across the board with the increase to 90 days at all institutions, it was highly correlated with the 30-day mortality. Of the 42 institutions evaluated, only 3 actually changed their benchmark outlier status. Thirty-day mortality appears to be an accurate way to evaluate overall hospital performance for coronary artery bypass

\footnotetext{
From the Department of Cardiothoracic Surgery, NYU Langone Health, New York, NY.

Disclosures: Consultant for Genentech, Inc.

The Journal policy requires editors and reviewers to disclose conflicts of interest and to decline handling or reviewing manuscripts for which they may have a conflict of interest. The editors and reviewers of this article have no conflicts of interest.

Received for publication April 19, 2020; accepted for publication April 20, 2020; available ahead of print May 1, 2020.

Address for reprints: Brian Mitzman, MD, Department of Cardiothoracic Surgery, NYU-Winthrop Hospital, $2591^{\text {st }}$ St, Mineola, NY 11501 (E-mail: Brian. Mitzman@nyulangone.org).

J Thorac Cardiovasc Surg 2022;163:683-4

$0022-5223 / \$ 36.00$

Copyright (c) 2020 by The American Association for Thoracic Surgery

https://doi.org/10.1016/j.jtcvs.2020.04.086
}

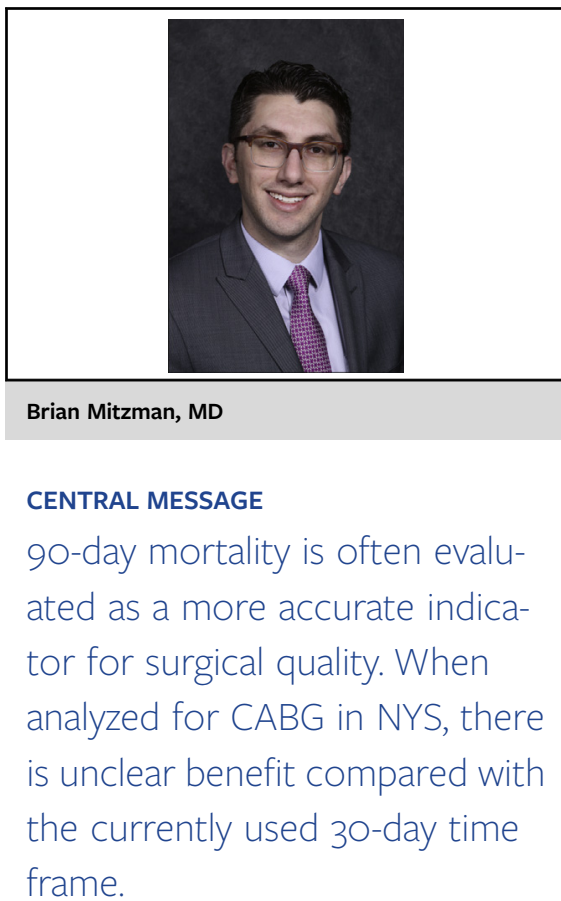

grafting. Although negative studies don't often have major implications on our field, this analysis is telling us to slow down, and that the data we already have may be good enough.

What are the reasons to consider using 90-day mortality instead of 30-day? The assumption is that a longer time frame will capture a more accurate total risk from surgical procedures. This has been analyzed in numerous fields, with a recent focus on oncologic surgery including lung and pancreatic resections. ${ }^{3,4}$ As Mittel and these other authors point out, a 90-day time frame more precisely captures the quality of extended postoperative surgical care as a contributor to mortality. In this study, results are consistent from institution to institution, however, and after this thorough analysis, 30-day mortality tends to give the same risk profile when compared with 90-day. The relative increase in mortality appears substantial $(70.8 \%)$, but the absolute risk is not $(1.53 \%)$. How about using 90 -day to paint the appropriate picture for patients and family members? Does it describe the true risk total risk of mortality, or is it misleading, as it likely includes factors not related to the procedure itself and will discourage patients to pursue surgery? We don't have the answer to this question, and it continues to be debated.

Mittel and colleagues provide an excellent example of appropriate large database analysis to answer a fairly granular question. They remind us that additional data do not always 
enhance our understanding of clinical outcomes, however, and that sometimes the data we already have are accurate.

\section{References}

1. Adult Cardiac Surgery in New York State 2014-2016. New York State Department of Health; 2019. Accessed April 18, 2020. Available at: https://health.ny.gov/statistics/ diseases/cardiovascular/heart_disease/docs/2014-2016_adult_cardiac_surgery.pdf.
2. Mittel AM, Kim DH, Cooper ZR, Argenziano M, Hua M. Use of 90-day mortality does not change assessment of hospital quality after coronary artery bypass grafting in New York State. J Thorac Cardiovasc Surg. 2022;163:676-82.e1.

3. Swanson RS, Pezzi CM, Mallin K, Loomis AM, Winchester DP. The 90-day mortality after pancreatectomy for cancer is double the 30-day mortality: more than 20,000 resections from the national cancer database. Ann Surg Oncol. 2014;21:4059-67.

4. Bryant AS, Rudemiller K, Cerfolio RJ. The 30- versus 90-day operative mortality after pulmonary resection. Ann Thorac Surg. 2010;89:1717-23.
See Article page 676.

\section{Commentary: Data - what is it good for?}

\author{
Pranav R. Shah, MD, ${ }^{a}$ and \\ John F. Butterworth IV, MD ${ }^{\mathrm{a}, \mathrm{b}}$
}

Cardiac surgery has been at the forefront of using quality metrics to drive improvement in patient care. The choice of interval after surgery to assess outcomes is thorny. When the interval is too short, one runs the risk of missing delayed adverse events that should clearly be associated with the surgical procedure. In contrast, given a long-enough interval, all patients will experience a wide variety of adverse events that are clearly NOT a reflection of perioperative quality. Thus, adverse neurobehavioral outcomes observed long after coronary artery bypass grafting (CABG) were almost certainly completely unrelated to the operation if they were not present at a 3-month assessment.

In this issue of the Journal, Mittel and colleagues ${ }^{2}$ investigated whether using 90-day rather than 30-day mortality after CABG would better inform quality comparisons. They reviewed all procedures in the New York State Planning and Research Cooperative System

From the ${ }^{a}$ Division of Cardiac Anesthesiology and Critical Care Medicine, and ${ }^{\mathrm{b}}$ Department of Anesthesiology, Virginia Commonwealth University School of Medicine, Richmond, Va.

Disclosures: The authors reported no conflicts of interest.

The Journal policy requires editors and reviewers to disclose conflicts of interest and to decline handling or reviewing manuscripts for which they may have a conflict of interest. The editors and reviewers of this article have no conflicts of interest.

Received for publication April 23, 2020; accepted for publication April 25, 2020; available ahead of print May 1, 2020.

Address for reprints: John F. Butterworth IV, MD, Department of Anesthesiology, Virginia Commonwealth University School of Medicine, PO Box 980695, Richmond, VA 23298-0695 (E-mail: jfbivjbutter@yahoo.com).

J Thorac Cardiovasc Surg 2022;163:684-5

$0022-5223 / \$ 36.00$

Copyright (c) 2020 by The American Association for Thoracic Surgery

https://doi.org/10.1016/j.jtcvs.2020.04.078
Check for updates

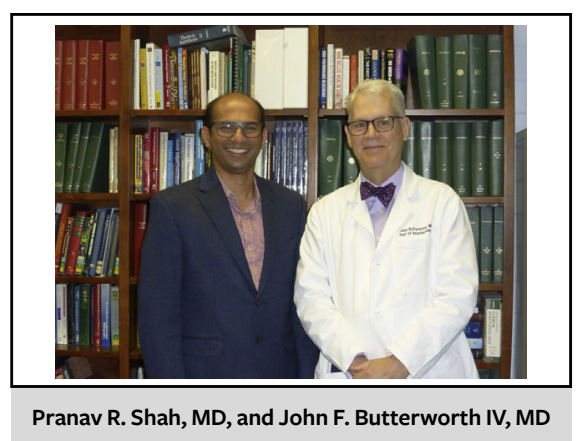

CENTRAL MESSAGE

Hospital comparative data should be meaningful to patients and physicians while providing guidance on how to improve.

(SPARCS) to identify adult New York (NY) State residents undergoing a CABG-only procedure at surgical centers performing at least 100 cardiac procedures per year in adults between 2008 and 2014. They linked this list with the NY State and NY City vital records to obtain 1-year mortality. After adjusting for patient and hospital characteristics (although not the "urgency" of the procedure), each institution was assigned a riskstandardized mortality rate. Institutions were stratified based on how they performed compared with the $95 \%$ confidence interval for their predicted/expected mortality ratio. Their results were as follows: 30-day mortality was $2.2 \%$ (interquartile range 0.69 ), and 90-day mortality was 3.7\% (interquartile range 1.0). At 30 days, 4 facilities were "good outliers" that performed better than expected, 33 facilities performed as "expected," and 5 facilities were "poor-performing outliers." When assessed using 90-day 